\title{
Polarity and CRTAM: a matter of timing
}

Activation of T cells by antigenpresenting cells requires the formation of an immunological synapse, which involves changes in membrane dynamics and cell polarity within the first few hours of contact, and the generation of secondary messengers that trigger cytokine production and T-cell effector functions. Now, Chan and colleagues describe a previously unrecognized late phase of cell polarity in some $\mathrm{CD} 4^{+} \mathrm{T}$ cells that is controlled by CRTAM (MHC-class-Irestricted T-cell-associated molecule)

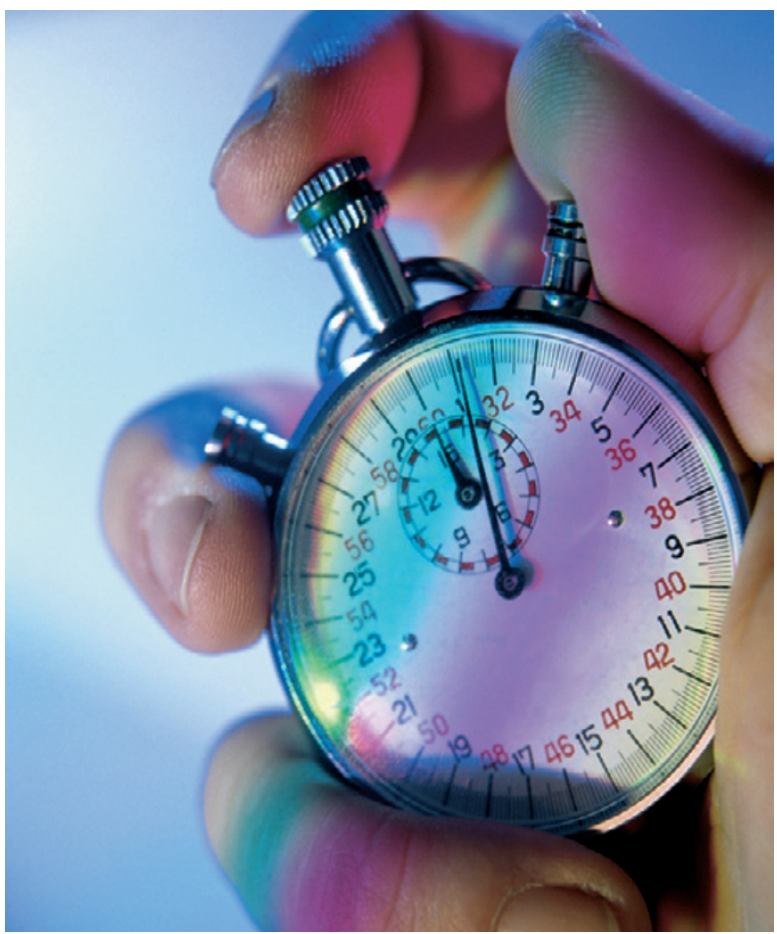

and that regulates interferon- $\gamma($ IFN $\gamma)$ and interleukin-22 (IL-22) production.

CRTAM is an immunoglobulinsuperfamily transmembrane protein that contains a PDZ domain, indicating that it might be capable of assembling protein complexes at the cell membrane. Here, the authors showed that CRTAM is transiently expressed, between 6 and 24 hours following T-cell receptor (TCR) ligation, on the surface of $\sim 10-40 \%$ of naive $\mathrm{CD} 4^{+} \mathrm{T}$ cells. Compared with wild-type cells, CRTAM-deficient $\mathrm{CD}^{+} \mathrm{T}$ cells produced lower levels of IFN $\gamma$ and IL-22 (and to a lesser extent IL-17), but similar levels of IL-4, and had a higher rate of proliferation following activation.

Within 5-30 minutes of TCR engagement, CD3, talin and other proteins such as protein kinase $\mathrm{C} \theta$ (PKC $\theta$ ) are known to be recruited to the TCR to form the immunological synapse. By studying later time points, Yeh et al. showed that co-localization of PKC $\theta$ with CD3 is no longer maintained. Instead, CRTAM, Scrib and PKC $\zeta$ co-localize with CD3 and talin at 8 and 12 hours following T-cell activation. Further analyses showed that CRTAM directly interacts with Scrib, which is known to be important in cell polarity, and that a loss of CRTAM expression resulted in a loss of T-cell polarity in this later phase of T-cell activation.

To further understand the role of CRTAM-Scrib interactions in T-cell polarity, the authors generated truncated CRTAM proteins that lacked either the entire intracellular domain or the Scrib binding site. In contrast to wild-type CRTAM, expression of these proteins in CRTAM-deficient $\mathrm{T}$ cells did not restore IFN $\gamma$ and IL-22 production nor the late phase polarization and did not reverse the hyperproliferative phenotype.

So, the expression of CRTAM by $\mathrm{CD}^{+} \mathrm{T}$ cells, through its interaction with Scrib and the formation of a signalling complex, regulates a previously unrecognized late phase of T-cell polarity, which is important for regulating IFN $\gamma$ and IL-22 production, as well as T-cell proliferation.

Olive Leavy

ORIGINAL RESEARCH PAPER Yeh, J.-H., Sidhu, S. S. \& Chan, A. C. Regulation of a late phase of T cell polarity and effector functions by $\mathrm{Crtam}$. Cell 132, 846-859 (2008) 